\title{
Introduction to the thematic issue: language policy and political theory
}

\author{
Yael Peled $\cdot$ Peter Ives $\cdot$ Thomas Ricento
}

Received: 19 May 2014 / Accepted: 20 May 2014/Published online: 11 July 2014

(C) Springer Science+Business Media Dordrecht 2014

The capacities for language and moral reasoning are two defining features of humanity. Both are central to policy and politics. They both also have a common paradoxical attribute in that the capacities for human language and moral agency are shared across humanity, but the particular languages and moralities generated by such capacities are very diverse and potentially at odds. Political theorists sometimes see such diverse moral values as the heart of politics. Language policy scholars are well aware that linguistic diversity is the central concern of policies concerning language use in its various forms from education policy, to language policy in the workplace, to support for endangered languages, to citizenship policies, and beyond. In this way, both language and moral reasoning can each be understood as a "dividing commonality" (Peled 2014).

In various ways, Language Policy and its readership are constantly grappling with this "dividing commonality" of language. The policy dilemmas, options and outcomes interrogated in the pages of this journal are premised on this dynamic within language. The second paradox frames a rather distinct sub-discipline of

\footnotetext{
Y. Peled

Centre de recherche en éthique de l'Université de Montréal (CRÉUM), Montreal, QC, Canada

e-mail: yael.peled@mcgill.ca

Y. Peled

Faculty of Law, McGill University, Montreal, QC, Canada

P. Ives

Political Science Department, University of Winnipeg, 515 Portage Ave., Winnipeg, MB R3B 2E9,

Canada

e-mail: p.ives@uwinnipeg.ca

T. Ricento $(\bowtie)$

Werklund School of Education, University of Calgary, 2500 University Drive, NW, Calgary,

AB T2N 1N4, Canada

e-mail: tricento@ucalgary.ca
} 
political science and philosophy most often called normative political theory. This Thematic Issue of Language Policy is premised on the idea that both areas of inquiry have much to gain from greater conversation and exchange. The contours of such interaction, however, can take many forms and directions. As co-editors of this Thematic Issue we are not proposing a single path, but rather are highlighting what we see as the substantial terrain that we need to grapple with in order to have a constructive, interdisciplinary dialogue engaging in the different advantages of methods, concepts, and concerns of both political theory concerned with language and language policy scholarship. Rather than apply the assumptions and presuppositions of a narrow tradition of normative political theory onto language policy as a topic, we wish to show how the debates within political theory can help enrich our understanding of the complexity of language policy. At the same time, we hope to demonstrate that the methods and findings from the language sciences should influence how political philosophers think and write about language.

One can begin by noting the matrix that results from recognizing the "dividing commonality" that pertains to language and morality. This matrix includes individuals who share both language and moral worldview, those who share either one but not the other, and those who share neither. None of these categories, of course, are rigid in any "Westphalian" sense, that is, discrete, fixed or close-ended: individuals may expand their linguistic repertoire and/or change their moral views. But, barring some radical reconfiguration of humanity's linguistic or ethical preferences, the complexity presented by this fundamental matrix remains irreducibly intact. We will never share a single language, nor be in complete agreement on what we view as the good life and/or the good state of society.

This irreducible matrix of humanity's "dividing commonality" is a good starting point for a meaningful discussion of the complex interface between language, power and ethics. Importantly, the interplay between linguistic diversity and the diversity of our moral views ought not to be perceived as a purely intellectual pursuit. Rather, language-related disagreements, tensions and conflicts comprise the everyday experience of a significant number of individuals, across political and linguistic boundaries. This is because our linguistic and moral difference is nevertheless constrained by our mutual interdependence on one another. On a global level, we are becoming increasingly more dependent on individuals whose language and morals we do not necessarily share. Global challenges such as the 2008 financial crisis or the current debate over climate change illustrate this interdependence best. Any hope for a successful response to such challenges necessitates cooperation that transcends linguistic borders and is grounded in common moral principles. Such a pathway would equally apply to the challenges of small linguistic minorities fighting to maintain their languages, challenges of multilingual polities that seek to advance a shared civic sphere, and challenges characterising the work of transnational political, educational and scientific bodies.

Unpacking the complex matrix of linguistic and ethical difference calls for a type of inquiry that builds on the respective disciplines of each subject matter, that is, linguistics and political science. Within each of these two disciplines, the matrix is best approached from the subfields of sociolinguistics and political theory. This has certainly been the case in the emerging debate on language and social justice on 
both sides of the disciplinary divide (e.g. in political philosophy Kymlicka and Patten 2003; De Schutter 2007, 2008; Castiglione and Longman 2008; Van Parijs 2011). In sociolinguistics see, (for example, Tollefson 1991; Freeland and Patrick 2004; Wee 2011, May 2011). The reason for this preference extends beyond the specialised subject matter to the particular form of inquiry that is most often associated with it. Sociolinguistics is generally guided by a strong commitment to empirical investigation that aims to identify and explore the "is" of the social life of human language. Political theory, by contrast, is substantially engaged with normative theorising, namely the systematic reflection over the "ought" of interpersonal relations and social institutions. ${ }^{1}$ Together, the two approaches can help us formulate an interdisciplinary framework that combines empirical analysis of sociolinguistic phenomena with systematic and theoretically rich normative evaluation. Language, power and ethics, of course, are never entirely divorced from each other. Sociolinguistic work often contains a normative element, just as political theory operates against a certain empirical backdrop. A combined inquiry, however, optimises the investigation by offering a systematic framework for analysing both empirical and normative aspects of power in language.

Such a combined framework, however, remains to date more of an emergent outline than a solid structure. The continual disengagement between language policy researchers and political philosophers remains a lamentable state of affairs, which directly and significantly affects the work produced in either subfield. It is also the backdrop from which this Thematic Issue emerges, with a clear intention to initiate closer contact between language policy scholars and political philosophers, around common questions and shared concerns, in order to advance a betterinformed inquiry on the interrelations between language, power and ethics. The hopeful prospects of a combined interdisciplinary perspective that brings together empirical and normative aspects require at this stage a considerable theory-building effort, one that is perhaps similar to the process that brought together linguistics and sociology in the early 1950s, resulting in the birth of sociolinguistics. At present it certainly lacks even a mutually recognizable label (despite the emerging notion of "normative language policy"), let alone shared theoretical, conceptual or methodological conventions. And while this Thematic Issue does not presume to provide definitive or authoritative answers to these voids, it aims to initiate and encourage a discussion from which they could eventually be developed.

The articles featured here provide a state-of-the-art overview on the interface between language policy and political theory, from researchers with a long-term commitment to an inquiry that seeks to go beyond thematic conventions and disciplinary borders. Taken together, the articles illustrate the evidently complex nature of any attempt to unpack that "dividing commonality" matrix, bringing in perspectives from critical theory (May, Ricento), analytical political theory (May, Ives, Peled, Ricento, Schmidt, Weinstock), intellectual history (Ives), political

\footnotetext{
1 This distinction between the two is certainly very general, and does not adequately reflect normative interests within sociolinguistics (e.g. critical applied linguistics) or empirical work within political theory (e.g. intellectual history, comparative political theory, comparative politics). Nevertheless, it does reflect general conventions in the respective fields, and as such provides a useful mapping of current work, approaches and trends.
} 
economics (Ricento), the philosophy of language (Ives) and complexity theory (Peled). Linguistic difference is discussed both between distinct recognisable varieties, or "languages" (May, Peled, Schmidt, Weinstock) and within them (Ives, Ricento). Difference in moral principles is addressed by exploring the competing views of liberalism (May, Ives, Ricento, Weinstock) and republicanism (Schmidt), and in the further unpacking of liberal theory in its political (May, Weinstock) and economic (Ricento) strands. The discussion further contains both focused attention to particular contexts and theoretical frameworks (May, Schmidt, Weinstock) alongside general engagement with the scientific epistemologies that underlie the debate (Ives, Peled, Ricento).

At the same time, the articles also share important commonalities. Most notably, these commonalities pertain less to localised problematic issues that require a particular "fix", and more to the broader terms that define the discussion as a whole. The call to "normalize" or "naturalize" linguistic diversity as a basic trait of individuals and societies is a strong thematic thread that runs through each of the contributions (e.g. Schmidt's notion of “ontological multilingualism" and May's appeal for "public multilingualism"). Linguistic difference, this common thread holds, is an undeniable reality of the human condition. The ubiquity of linguistic difference re-emphasizes the reality of human interdependence, and the empirical social, political and economic dynamics that govern it (Ricento's split market analysis of English and Weinstock's collective action framework). It also identifies subtler and more intricate forms of interdependence, such as epistemic (Ives) and adaptive (Peled). Such an analysis highlights in turn the crucial importance of human cooperation in the face of local and global challenges, and the need to find morally justifiable pathways towards such cooperation. In other words, linguistic difference is here to stay. What we need to figure out is a way to determine which ways of handling this difference are better or worse than others.

Another important common thread that runs through the majority of the articles is a repeated appeal for a greater analytical sensitivity towards intralinguistic variants. Political theory as a general rule dedicates a significant amount of effort to making fine-grained conceptual distinctions (e.g. equality of opportunities vs. equality of resources). This is particularly the case in analytical political theory, which is the strand of work that is chiefly discussed by the contributors to this Thematic Issue. An overarching critique of the analysis of language in political theory that emerges from these articles makes the point that contemporary work tends to focus its attention on interlinguistic (e.g. between English and French) rather than intralinguistic (e.g. between variants of English) analysis. Within the already limited body of work on normative theorising in language, intralinguistic analysis certainly remains almost entirely unexplored. ${ }^{2}$ By calling for greater sensitivity towards intralinguistic variance, the articles included in this issue do not so much seek to supplant the analytical approach of contemporary political theory, as to revise the linguistic contexts in which it operates.

\footnotetext{
${ }^{2}$ For rare notable exceptions see Wee (2011) in sociolinguistics and De Schutter's "Intralinguistic Justice" in political theory (De Schutter 2014)
} 
The interface between language, power and ethics is a complex and an evolving one, which stems from the irreducible tension between our linguistic and moral differences on the one hand, and our inescapable interdependence on the other. The systematic inquiry into this complex interface is at present only in its inceptive stages, as is evidenced by the plurality of approaches and perspectives that are featured in this Thematic Issue, and by the efforts that were required of the contributors to identify and bring into focus these various approaches and perspectives. The present emergent state of the debate on normative theorising in language policy should not be a cause for concern, but rather viewed as a timely opportunity for significant theorybuilding efforts, which may potentially advance the theoretical understanding of language in society, and promote more fine-tuned real-world public policy measures. In the development process of a combined interdisciplinary framework for achieving these ends, the purpose of this Thematic Issue is not to provide finite solutions or prescribe immediate fixes, whether linguistic or political. Rather, it intends to raise a set of issues it identifies as central to the debate, to refine existing questions into better ones, and to open the discussion to researchers in different disciplines with a shared interest in the interplay of language policy and political theory.

\section{References}

Castiglione, D., \& Longman, C. (Eds.). (2008). The language question in Europe and diverse societies: Political, legal and social perspectives. Oxford: Hart Publishing.

De Schutter, H. (2007). Language policy and political philosophy: On the emerging linguistic justice debate. Language Problems and Language Planning, 31(1), 1-23.

De Schutter, H. (2008). The linguistic territoriality principle: A critique. Journal of Applied Philosophy, 25(2), 105-120.

De Schutter, H. (2014). Intralinguistic justice. Unpublished paper, Katholieke Universiteit Leuven, Belgium.

Freeland, J., \& Patrick, D. (Eds.). (2004). Language rights and language survival. Manchester: St. Jerome Publishing.

Kymlicka, W., \& Patten, A. (Eds.). (2003). Language rights and political theory. Oxford: Oxford University Press.

May, S. (2011). Language and minority rights: Ethnicity, nationalism and the politics of language (2nd ed.). London: Routledge.

Peled, Y. (2014). Language ethics as a field of inquiry. Unpublished paper, Université de Montréal and McGill University, Montreal, QC, Canada.

Tollefson, J. (1991). Planning language, planning inequality: Language policy in the community. London: Longman.

Van Parijs, P. (2011). Linguistic justice for Europe and for the world. Oxford: Oxford University Press. Wee, L. (2011). Language without rights. Oxford: Oxford University Press.

Yael Peled is a Banting Postdoctoral Fellow at the Centre de recherche en éthique de l'Université de Montréal (CRÉUM) and the Department of Philosophy and Faculty of Law at McGill University. She received a B.A degree in political science and general linguistics from the Hebrew University of Jerusalem, and a DPhil in political philosophy from Nuffield College, University of Oxford. She held fellowships at the Hebrew University, the Van Leer Jerusalem Institute, Universite catholique de Louvain, and King's College London. Her research focuses on language ethics, linguistic justice, normative language policy, adaptive political theory, and the application of complex adaptive systems to public policy (including language policy) ethics research. 
Peter Ives is Professor of Political Science at the University of Winnipeg, Canada. He is author of Gramsci's Politics of Language: Engaging the Bakhtin Circle and the Frankfurt School (University of Toronto Press, 2004); Language and Hegemony in Gramsci (Pluto Press, 2004) and co-editor with Rocco Lacorte of Gramsci, Language and Translation (Lexington, 2010). His articles on the political implications of the advent of 'global English' have been published in Political Studies, Educational Philosophy and Theory, and Studies in Language and Capitalism as well as various edited collections. His writings have been translated into Spanish, German, Italian, Portuguese and Turkish. He is a member of the editorial collective of ARP Books, an independent progressive publishing house.

Thomas Ricento is the editor of the following books: An Introduction to Language Policy: Theory and Method (Blackwell, 2006); Ideology, Politics, and Language Policies: Focus on English (John Benjamins, 2000); co-editor (with Barbara Burnaby) of Language and Politics in the United States and Canada: Myths and Realities (Lawrence Erlbaum, 1998); and editor of Language Policy and Political Economy: English in a Global Context (Oxford University Press, in press). He has published research on language policy and language ideology in TESOL Quarterly, Journal of Sociolinguistics, Discourse \& Society, International Journal of the Sociology of Language, Critical Multilingualism Studies, and Journal of Multilingual and Multicultural Development, among other journals. He is founding co-editor of the Journal of Language, Identity, and Education (Routledge) and has been a visiting professor at universities in Spain, Switzerland, Chile, Costa Rica, and Colombia. He was twice a Fulbright Professor (Colombia and Costa Rica) and has been awarded research grants from the Russell Sage Foundation, the National Endowment for the Humanities, and Social Sciences and Humanities Research Council (Canada), among other funders. 